\title{
Insulin-Like Growth Factor Axis Expression in Dental Pulp Cells Derived From Carious Teeth
}

\author{
Hanaa Esa Alkharobi1,2, Hasanain Al-Khafaji, ${ }^{1,2}$, James Beattie ${ }^{1}$, Deirdre Ann Devine ${ }^{1}$ \\ and Reem El-Gendy,3*
}

\begin{abstract}
${ }^{1}$ Division of Oral Biology, Leeds School of Dentistry, St James University Hospital, University of Leeds, Leeds, United Kingdom, ${ }^{2}$ Department of Oral Biology, Faculty of Dentistry, King Abdul Aziz University, Jeddah, Saudi Arabia, ${ }^{3}$ Department of Oral Pathology, Faculty of Dentistry, Suez Canal University, Ismailia, Egypt
\end{abstract}

\section{OPEN ACCESS}

Edited by:

Rania El Backly,

Alexandria University, Egypt

Reviewed by:

Samer Zaky,

University of Pittsburgh,

United States

Roberta Tasso,

Ospedale San Martino

(IRCCS), Italy

*Correspondence:

Reem El-Gendy

R.El-Gendy@/eeds.ac.uk

Specialty section:

This article was submitted

to Tissue Engineering and

Regenerative Medicine,

a section of the journal

Frontiers in Bioengineering

and Biotechnology

Received: 19 January 2018

Accepted: 15 March 2018

Published: 12 April 2018

Citation:

Alkharobi HE, Al-Khafaji H, Beattie J, Devine DA and El-Gendy $R$ (2018) Insulin-Like Growth Factor Axis Expression in Dental Pulp Cells

Derived From Carious Teeth.

Front. Bioeng. Biotechnol. 6:36. doi: 10.3389/fbioe.2018.00036
The insulin-like growth factor (IGF) axis plays an important role in dental tissue regeneration and most components of this axis are expressed in human dental pulp cells (DPCs). In our previous study, we analyzed IGF axis gene expression in DPCs and demonstrated a novel role of IGF binding protein (IGFBP)-2 and -3 in coordinating mineralized matrix formation in differentiating DPCs. A more recent study from our laboratory partially characterized dental pulp stem cells from teeth with superficial caries (cDPCs) and showed that their potential to differentiate odontoblasts and/or into osteoblasts is enhanced by exposure to the mild inflammatory conditions characteristic of superficial caries. In the present study, we examine whether changes apparent in IGF axis expression during osteogenic differentiation of healthy DPCs are also apparent in DPCs derived from carious affected teeth.

Keywords: insulin-like growth factor axis, IGF binding protein-3, IGF binding proteins-2, dental pulp stem cells, inflammation, pulp regeneration, caries, dentin

\section{INTRODUCTION}

Dental caries is one of the most prevalent chronic diseases worldwide (Selwitz et al., 2007). It is a result of complex interaction over time between acid-producing bacteria and fermentable carbohydrate, and other host factors including saliva (Selwitz et al., 2007). Penetration of oral bacteria into the dentin layer triggers inflammatory responses in the dental pulp (Farges et al., 2015), which responds to injury or inflammation according to the severity of infection (mild versus deep caries). The inflammatory process is characterized by inflammatory cell infiltrate and immature progenitor cell recruitment (Chen et al., 2006). DPC biology is known to be affected by caries, but further studies are needed to determine in detail the causative molecular mechanisms associated with these processes. DPCs themselves have immunomodulatory effects and have been successfully isolated from inflamed dental pulps (Alongi et al., 2010). Interestingly, these cells showed high expression levels of some mesenchymal stem cell markers (Chen and Thouas, 2011) although there is some controversy in relation to their differentiation potential in comparison with cells isolated from normal pulp (McLachlan et al., 2004; Ma et al., 2012). cDPCs were found to have a higher mineralization potential as well as a higher expression of gene associated with osteogenesis and/or odontogenesis, compared to hDPCs (Alkharobi et al., 2017). The rate of dentin repair/regeneration is closely related to the population size of remaining vital odontoblasts or newly differentiated odontoblast-like cells. If the inflammation is not too severe and/or is rapidly controlled, then innate pulp repair mechanisms can generally suffice for regeneration of the tissue (Farges et al., 2015). Carious teeth are usually extracted 
and discarded; however, as indicated above these cells are also a potential source of DPCs (Alongi et al., 2010; Werle et al., 2016).

The insulin-like growth factor (IGF) axis comprises two polypeptide growth factors (IGF-1 and IGF-2), two cell surface receptors (IGF-1R and IGF-2R), and six high affinity, soluble IGF binding proteins (IGFBP1-6) The IGF axis is known to play a role in the differentiation of progenitor cells into dental mineralized tissue (Gotz et al., 2006a; Chen et al., 2010; Abreu et al., 2013) being associated with the induction of enamel bio-mineralization (Takahashi et al., 1998), the differentiation of dental pulp cells (DPCs) (Onishi et al., 1999), and reparative dentinogenesis (Lovschall et al., 2001). Liposomal delivery of IGF1 along with calcium hydroxide into the tooth socket enhanced the deposition of osteodentin-like matrix around dental implants (Tziafas et al., 1998). Similarly, IGF-1 in combination with platelet-derived growth factor and calcium hydroxide improved healing of apical tooth perforations in a canine model. Further evidence suggested that IGF-1 regulated the balance between odontogenesis and osteogenesis in apical papilla stem cells (Wang et al., 2012) and IGF-1 enhances odontogenic differentiation and deposition of extracellular matrix in differentiating DPCs ( $\mathrm{Li}$ et al., 1998; Onishi et al., 1999). IGF-2 was reported to be expressed by DPCs at both gene and protein levels, although its function in this tissue is still largely unknown (Shi et al., 2001). IGF-1R showed higher expression in teeth with incomplete root development, suggesting a role for IGF-1 in this process (Caviedes-Bucheli et al., 2004). IGFBP-1, $-3,-5$, and -6 have also been detected in DPCs isolated from healthy premolars and third molars (Gotz et al., 2006b).

In our previous study, we analyzed IGF axis gene expression in DPCs and demonstrated a novel role of IGFBP-2 and -3 in coordinating mineralized matrix formation (Alkharobi et al., 2016). A more recent study from our laboratory partially characterized DPCs from teeth with superficial caries (cDPCs) and showed that their potential to differentiate to a matrix mineralizing phenotype is enhanced by exposure to the mild inflammation characteristic of superficial caries (Alkharobi et al., 2017). In the current study, we aimed to determine whether the changes in IGF axis expression characteristic of differentiating hDPCs were also seen during differentiation of cDPCs.

\section{MATERIALS AND METHODS}

\section{Tissue Culture}

Freshly extracted carious fully erupted third molars were collected from three adult patients (20-40 years of age) at the outpatient's dental clinic of Leeds Dental Institute. Teeth were obtained through Leeds Dental and Skeletal tissue bank (under the approval of the Leeds University Dental Research Ethics Committee number 130111/AH/75), with patients' informed consent (Alkharobi et al., 2017). Carious lesions in this study were chosen based on the depth of the decay in the dentin layer which was assessed in this group during the sectioning of the teeth. Teeth with more than $2 \mathrm{~mm}$ of sound dentin measured from the edge of carious lesion to the pulp tissue, were included in this study and categorized as shallow caries lesions (McLachlan et al., 2004; Gallego et al., 2010). This was assessed visually and using a WHO periodontal probe. Single cell suspensions were created by collagenase digestion of the isolated pulps as previously described (Alkharobi et al., 2016, 2017). cDPCs at passage 4 were cultured in 6 -well plates at $10^{5}$ cells/well under basal conditions [ $\alpha$-MEM supplemented with 20\% (v/v) FBS, $200 \mathrm{mM}$ L-glutamine, and 100 unit/ml Pen Strep]. When the cells reached $80 \%$ confluence, they were cultured in triplicate under basal or mineralizing/osteogenic conditions (basal medium $+10 \mathrm{nM}$ dexamethasone and $100 \mu \mathrm{M}$ of L-ascorbic acid).

\section{qRT-PCR}

RNeasy ${ }^{\circledR}$ Mini Kit (Qiagen, UK) was used to extract and purify mRNA exactly according to the manufacturer's protocol. mRNA quality was confirmed by monitoring A260/280 ratios and $1 \mu \mathrm{g}$ mRNA was used for first strand cDNA synthesis using High Capacity mRNA to cDNA kit (Applied Biosystems, UK) exactly according to the manufacturer's protocol. qRT-PCR reactions were conducted in a total volume of $20 \mu \mathrm{l}$ using TaqMan probes and primers. Reactions were amplified using the Roche 480 Light Cycler ${ }^{\circledR}$. Gene expression analysis was carried out using the $\Delta \Delta \mathrm{Ct}$ method, which is plotted as ordinate and indicates fold differences in expression mineralizing versus basal. TaqMan assay identifiers for each gene are presented in Table $\mathbf{1 .}$

\section{ELISA}

IGF binding protein-2 and IGFBP-3 concentrations in conditioned media were determined by enzyme-linked immunosorbent assay (R\&D Systems, UK) exactly according to the manufacturer's protocol and as described previously (Alkharobi et al., 2016). $1 \mathrm{ml}$ of conditioned medium ( $24 \mathrm{~h}$ conditioning period; $3 \times 10^{5}$ cells) was collected from basal and mineralizing cultures at both 1 - and 3-week time points, centrifuged briefly to remove cell debris and stored at $-80^{\circ} \mathrm{C}$ prior to assay. Unconditioned medium was used as a negative control. Standard curves for ELISA were constructed in unconditioned medium and were linear between 0.0625 and $4 \mathrm{ng} / \mathrm{ml}$ (IGFBP-2) and $0.781-50 \mathrm{ng} / \mathrm{ml}$ (IGFBP-3). Samples of conditioned medium were appropriately diluted in unconditioned medium (total volume $=50 \mu \mathrm{l}$ ) to fall in this region of the standard curve. Assays were performed on media conditioned by cDPC cultures

TABLE 1 | Assay identifiers for TaqMan qRT-PCR.

\begin{tabular}{lr} 
Gene name & TaqMan ${ }^{\circledR}$ Gene expression assay \\
\hline GAPDH & Hs99999905_m1 \\
IGF1 & Hs01547656_m1 \\
IGF2 & Hs04188276_m1 \\
IGF1R & Hs00609566_m1 \\
IGF2 R & Hs00974474_m1 \\
IGFBP1 & Hs00236877_m1 \\
IGFBP2 & Hs01040719_m1 \\
IGFBP3 & Hs00426289_m1 \\
IGFBP4 & Hs01057900_m1 \\
IGFBP5 & Hs00181213_m1 \\
IGFBP6 & Hs00181853_m1
\end{tabular}

Further details available at www.appliedbiosystems.com 
derived from three separate donors and were typically assayed as technical triplicates. Data are presented as $\mathrm{ng} / \mathrm{ml}$ (mean $\pm \mathrm{SD}$ ).

\section{Statistics}

Statistical analysis was carried out for gene expression results on individual donors $(n=3)$ and for global gene expression data, using one way ANOVA followed by Bonferroni multiple comparison tests, using Graph Pad Prism software (v 6). Differences were considered significant when $p$ values were $<0.05$.

Statistical analysis of IGFBP-2 and IGFBP-3 protein concentrations in basal and osteogenic conditioned medium was by unpaired $t$-test and was considered significant at $p<0.05$ (B versus O). Graphpad Prism version 6.

\section{RESULTS}

\section{IGF Axis Expression}

In differentiating cDPCs only IGF2 and IGFBP-2 were upregulated consistently at week 1 and week 3 in all donors (Figure 1). At the week 1 time point, both IGF2 and IGFBP-2 were upregulated approximately threefold. At the 3 week time point, IGF2 expression was upregulated almost 30 -fold and $I G F B P-2$ approximately 10 -fold. Conversely, IGBP-3 was consistently downregulated in CDPCs from all donors (Figure 1). At the 1 week time point, IGFBP-3 was downregulated 20 -fold at the 3 -week time point around 4-fold. Changes in IGFBP-2 and IGFBP-3 mRNA expression under osteogenic conditions in CDPCs were reflected in corresponding changes in protein concentration in conditioned medium (Figure 2). For IGFBP-2 at week 1 protein concentrations in conditioned medium were $5.3 \pm 1.5$ versus $10.1 \pm 2.4 \mathrm{ng} / \mathrm{ml} \mathrm{B}$ versus $\mathrm{O}(n=7-9$ mean \pm SEM). At the 3 week time point, IGFBP-2 concentrations were $11.0 \pm 2.7$ versus $38.3 \pm 4.9 \mathrm{ng} / \mathrm{ml} \mathrm{B}$ versus $\mathrm{O}(n=7-8$ mean $\pm \mathrm{SEM})$. At the week 3 time point, this difference was considered significant $p<0.05$ and at the week 1 time point approached significance $(p=0.11)$. For IGFBP-3 protein concentrations in conditioned medium at week 1 time point were $0.93 \pm 0.13$ versus $0.10 \pm 0.03 \mathrm{ng} / \mathrm{ml} \mathrm{B}$ versus $\mathrm{O}(n=9$ mean $\pm \mathrm{SEM})$. At the 3 week time point, protein concentrations were $5.2 \pm 1.7$ versus $1.5 \pm 0.27 \mathrm{ng} / \mathrm{ml} \mathrm{B}$ versus $\mathrm{O}(n=8 \pm \mathrm{SEM})$. At 1 week, this difference was significant at $p<0.05$ and at week 3 was close to significance $(p=0.051)$. For IGF1R, IGF2R, IGFBP-4, -5 , and -6 there was no significant difference in mRNA or protein concentrations basal versus osteogenic (data not shown). In our hands, expression of both IGF1 and IGFBP-1 was very low $(\mathrm{Ct}>35)$ under both basal and osteogenic conditions (data not shown).

\section{DISCUSSION}

The expression of the IGF axis under mineralizing/osteogenic conditions in cDPCs has not previously been reported. The current study showed that IGF-1 was expressed at very low levels by cDPCs confirming our previous observations in hDPCs. Literature concerning IGF1 expression in dental tissue derived cells is scarce and at times contradictory. Joseph et al. showed

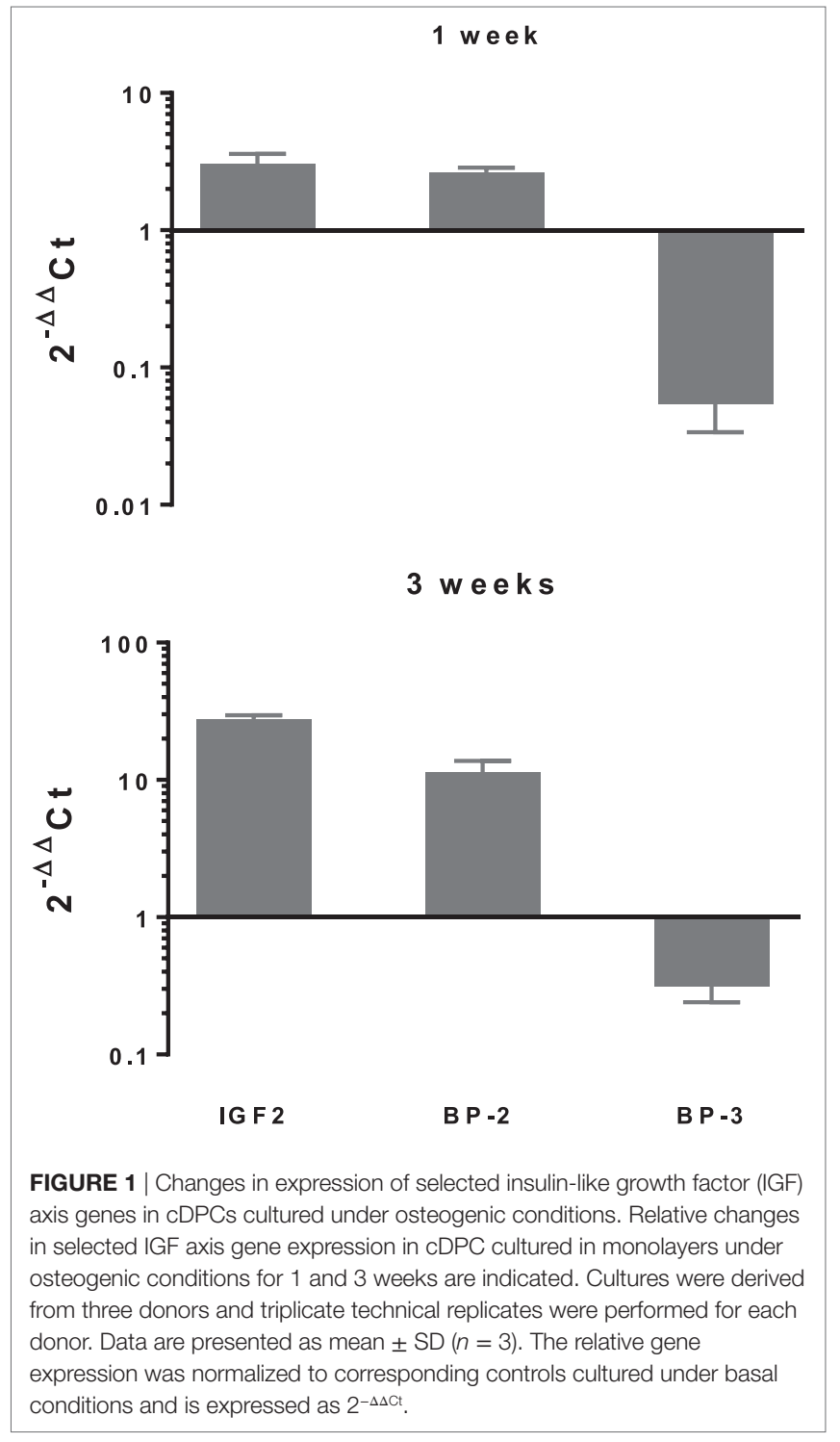

IGF1 mRNA expression in cells derived from the apical loop and in secretory ameloblasts in the continuously erupting rat incisor model. However, in agreement with our data, IGF1 mRNA was low or absent in dental pulp derived cells (Joseph et al., 1996). However, using immunohistochemical techniques, IGF1 peptide was identified in human dental pulps with expression levels correlated with the stage of root development (CaviedesBucheli et al., 2009). It is well established that DPC in culture respond to exogenous IGF1 (Li et al., 1998; Onishi et al., 1999), therefore, further investigation of endogenous IGF1 expression in DPCs would allow some conclusion regarding autocrine/ paracrine versus endocrine actions of IGF1 in dental pulp tissue. IGF-2 mRNA expression demonstrated consistent upregulation in cDPCs under mineralizing/osteogenic conditions at 1 and 3 week time points again confirming previous observations in hDPCs. We have recently confirmed that IGF2 peptide is present at 10-fold higher concentrations in differentiated DPCs compared to cells grown under basal conditions (Al-Khafaji 


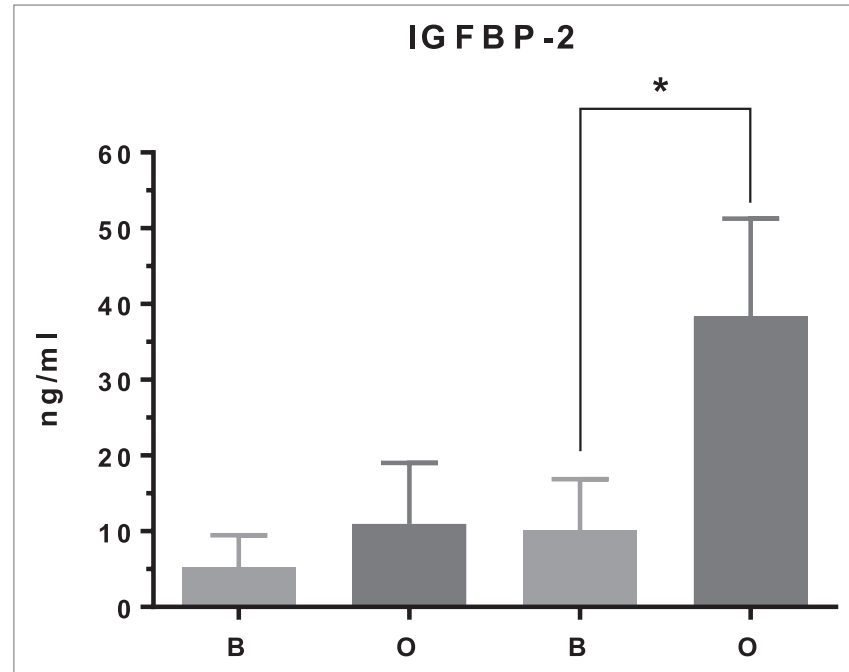

IG F B P -3

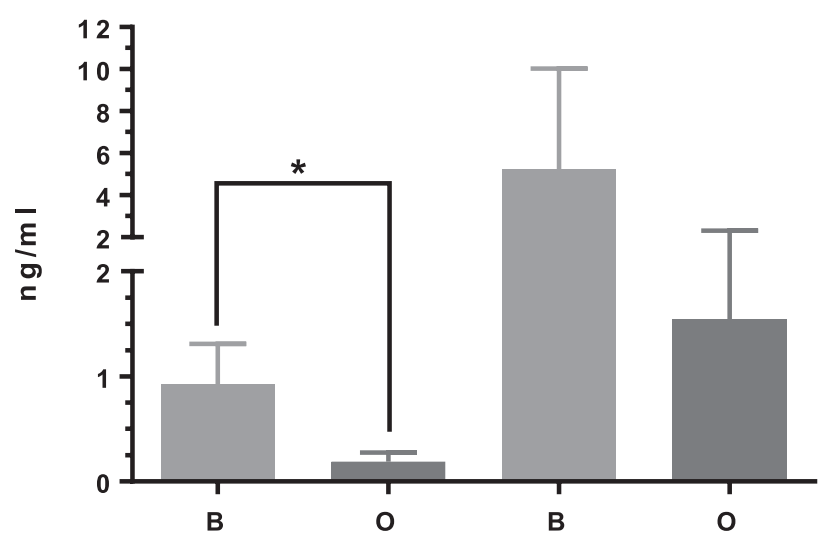

FIGURE 2 | IGF binding protein (IGFBP)-2 and IGFBP-3 protein concentration in CDPC cultured under basal or mineralizing conditions. Media was conditioned by cells from three separate donors grown under basal or osteogenic conditions at both 1- and 3-week time points. Assays were performed as technical triplicates for each donor and are presented as mean \pm SEM $(n=7-9)$ in nanogram per milliliter for each protein $\left(^{\star} p<0.01\right)$.

et al. submitted for publication). We believe our data represent the first demonstration of increased IGF2 expression under mineralization conditions in DPCs and confirm previous findings that IGF2 is the main IGF species expressed in dental pulp (Reichenmiller et al., 2004). IGF2 may be sequestered in the matrix during dentin formation and released during demineralization of dentin. This may to some extent explain the pattern of $I G F-2$ gene expression in cDPCs observed in the current study. Interestingly, IGF-2 was highly expressed in DPCs isolated from deciduous teeth, where the pulp was exposed during the removal of proximal caries.

We have demonstrated reproducible upregulation of IGFBP2 gene expression in cDPCs under mineralizing/osteogenic conditions at 1 and 3 week time points. These findings were mirrored in the results for protein concentrations in conditioned medium. As such these findings confirm our previous observations in hDPCs (Alkharobi et al., 2016). There is very little data on the expression and activity of any of the IGFBP gene family in dental tissues, however, the involvement of IGFBP-2 in enhanced osteogenesis was suggested by the observation of skeletal thickening associated with elevated serum IGFBP-2 levels in hepatitis-associated osteosclerosis (Khosla et al., 1998). Although there are some reports of inhibitory effects of IGFBP-2 on bone size, mass, and proliferation of rat calvarias derived cells (Feyen et al., 1991; Eckstein et al., 2002), consensus opinion appears to favor an anabolic role of IGFBP-2 in osteogenesis either complexed with IGFs or acting independently of the growth factor (Conover and Khosla, 2003; Hamidouche et al., 2010).

In this study, IGFBP-3 was consistently downregulated in cDPCs under mineralizing conditions again confirming previous data in hDPCs. Early studies suggested that the expression of IGFBP-3 can be regulated by glucocorticoids such as dexamethasone. Glucocorticoids inhibit IGFBP-3 expression in hepatocytes (Villafuerte et al., 1995) and fibroblasts (Conover et al., 1995), although this synthetic glucocorticoid is also reported to upregulate $I G F B P-3$ expression in vivo. Based on these reports, the levels of IGFBP-3 in the current study might be downregulated due to the effect of dexamethasone in the mineralizing differentiation culture medium. Another group who investigated IGFBP-3 expression in an odontoblast-like cell line cultured in non-dexamethasone containing medium confirmed the expression of IGFBP-3 at later stages (25 days) of differentiation (Caton et al., 2007). However, Jia and Heersche (2002) reported that IGFBP-3 gene expression was lower in dexamethasone-treated cultures at day 20 but higher at day 8 and day 14 than in basal cultures. The use of dexamethasone free differentiation medium may, therefore, be indicated for future experiments and it would be interesting to compare the results of such experiments with those reported in the current study.

In contrast to our findings, Reichenmiller et al. (2004) reported that IGFBP-2 concentrations decreased slightly, while IGFBP-3 increased during differentiation of human pulp cells isolated from healthy third molars. There are several possible explanations for this contradiction, Reichenmiller et al. (2004) assayed the cell extracts (and thus intracellular IGFBPs) to determine the protein concentration of IGFBP-2 and IGFBP-3, while in the current study these proteins were measured in conditioned media. IGFBPs are essentially secreted proteins, and therefore media conditioned by DPCs are considered more appropriate sources to investigate IGFBP-2 and IGFBP-3 concentrations in vitro. In addition, Reichenmiller et al. (2004) did not treat the cells with dexamethasone, or ascorbic acid but simply allowed confluent cells to differentiate in basal medium. Furthermore, our current findings showing IGFBP-2 upregulation in mineralizing medium containing dexamethasone confirms previous observations (Jia and Heersche, 2002). In the current study, IGFBP-2 and IGFBP-3 levels were higher in cDPCs compared to cells isolated form healthy teeth (Alkharobi et al., 2016). The mild inflammatory environment associated with superficial caries is known to activate NF-kB (Lawrence, 2009) and following nuclear translocation NF-kB activates expression of numerous target genes including IGFBPs (Shoelson et al., 2006). 


\section{CONCLUSION}

This study confirms that the changes in IGF expression previously reported in DPCs derived from healthy dental pulps are replicated in DPCs derived from carious lesions and suggests that similar IGF axis-based regulation of mineralization may occur in cDPCs.

\section{ETHICS STATEMENT}

In this study we used freshly extracted carious fully erupted third molars collected from adult patients (20-40 years of age) at the outpatient's dental clinic of Leeds Dental Institute. Teeth were obtained through Leeds Dental and Skeletal tissue bank (LDI Research Tissue Bank; 130111/AH/75), with patients' informed consent.

\section{REFERENCES}

Abreu, F. A., Ferreira, C. L., Silva, G. A., Paulo Cde, O., Miziara, M. N., Silveira, F. F., et al. (2013). Effect of PDGF-BB, IGF-I growth factors and their combination carried by liposomes in tooth socket healing. Braz. Dent. J. 24, 299-307. doi:10.1590/0103-6440201302238

Alkharobi, H., Alhodhodi, A., Hawsawi, Y., Alkafaji, H., Devine, D., El-Gendy, R., et al. (2016). IGFBP-2 and -3 co-ordinately regulate IGF1 induced matrix mineralisation of differentiating human dental pulp cells. Stem Cell Res. 17, 517-522. doi:10.1016/j.scr.2016.09.026

Alkharobi, H., Beattie, J., Meade, J., Devine, D., and El-Gendy, R. (2017). Dental pulp cells isolated from teeth with superficial caries retain an inflammatory phenotype and display an enhanced matrix mineralization potential. Front. Physiol. 8:244. doi:10.3389/fphys.2017.00244

Alongi, D. J., Yamaza, T., Song, Y., Fouad, A. F., Romberg, E. E., Shi, S., et al. (2010). Stem/progenitor cells from inflamed human dental pulp retain tissue regeneration potential. Regen. Med. 5, 617-631. doi:10.2217/rme.10.30

Caton, J., Bringas, P. Jr., and Zeichner-David, M. (2007). Establishment and characterization of an immortomouse-derived odontoblast-like cell line to evaluate the effect of insulin-like growth factors on odontoblast differentiation. J. Cell. Biochem. 100, 450-463. doi:10.1002/jcb.21053

Caviedes-Bucheli, J., Canales-Sanchez, P., Castrillon-Sarria, N., Jovel-Garcia, J., Alvarez-Vasquez, J., Rivero, C., et al. (2009). Expression of insulin-like growth factor-1 and proliferating cell nuclear antigen in human pulp cells of teeth with complete and incomplete root development. Int. Endod. J. 42, 686-693. doi:10.1111/j.1365-2591.2009.01568.x

Caviedes-Bucheli, J., Munoz, H. R., Rodriguez, C. E., Lorenzana, T. C., Moreno, G. C., and Lombana, N. (2004). Expression of insulin-like growth factor-1 receptor in human pulp tissue. J. Endod. 30, 767-769. doi:10.1097/01.DON.0000134203. $65706.8 \mathrm{~F}$

Chen, L., Jiang, W., Huang, J., He, B. C., Zuo, G. W., Zhang, W., et al. (2010). Insulinlike growth factor 2 (IGF-2) potentiates BMP-9-induced osteogenic differentiation and bone formation. J. Bone Miner. Res. 25, 2447-2459. doi:10.1002/ jbmr.133

Chen, Q. Z., and Thouas, G. A. (2011). Fabrication and characterization of sol-gel derived 45S5 Bioglass (R)-ceramic scaffolds. Acta Biomater. 7, 3616-3626. doi:10.1016/j.actbio.2011.06.005

Chen, S. C., Marino, V., Gronthos, S., and Bartold, P. M. (2006). Location of putative stem cells in human periodontal ligament. J. Periodont. Res. 41, 547-553. doi:10.1111/j.1600-0765.2006.00904.x

Conover, C. A., Durham, S. K., Zapf, J., Masiarz, F. R., and Kiefer, M. C. (1995). Cleavage analysis of insulin-like growth factor (IGF)-dependent IGF-binding protein-4 proteolysis and expression of protease-resistant IGF-binding protein4 mutants. J. Biol. Chem. 270, 4395-4400. doi:10.1074/jbc.270.9.4395

Conover, C. A., and Khosla, S. (2003). Role of extracellular matrix in insulin-like growth factor (IGF) binding protein-2 regulation of IGF-II action in normal human osteoblasts. Growth Horm. IGF Res. 13, 328-335. doi:10.1016/S10966374(03)00092-3

\section{AUTHOR CONTRIBUTIONS}

HA and HA-K carried out the experimental work and the analysis of the data. JB and RE-G conceived the study contributed to the experimental design and analysis of data. JB, RE-G, and DD supervised the project. RE-G wrote the manuscript.

\section{FUNDING}

HA acknowledges the Royal Embassy of Saudi Arabia—Cultural Bureau (UK) for financial support. HA-K acknowledges the Higher Education Committee for Education and Development (HCED), Office of Prime Minister, Iraq for financial support. RE-G acknowledges WELMEC a Centre of Excellence in Medical Engineering funded by Wellcome Trust and EPSRC under grant number WT088908/Z/09/Z for financial support.

Eckstein, F., Pavicic, T., Nedbal, S., Schmidt, C., Wehr, U., Rambeck, W., et al. (2002). Insulin-like growth factor-binding protein-2 (IGFBP-2) overexpression negatively regulates bone size and mass, but not density, in the absence and presence of growth hormone/IGF-I excess in transgenic mice. Anat. Embryol. (Berl) 206, 139-148. doi:10.1007/s00429-002-0282-5

Farges, J. C., Alliot-Licht, B., Renard, E., Ducret, M., Gaudin, A., Smith, A. J., et al. (2015). Dental pulp defence and repair mechanisms in dental caries. Mediators Inflamm. 2015, 230251. doi:10.1155/2015/230251

Feyen, J. H., Evans, D. B., Binkert, C., Heinrich, G. F., Geisse, S., and Kocher, H. P. (1991). Recombinant human [Cys281]insulin-like growth factor-binding protein 2 inhibits both basal and insulin-like growth factor I-stimulated proliferation and collagen synthesis in fetal rat calvariae. J. Biol. Chem. 266, 19469-19474.

Gallego, L., Junquera, L., Meana, A., Garcia, E., and Garcia, V. (2010). Threedimensional culture of mandibular human osteoblasts on a novel albumin scaffold: growth, proliferation, and differentiation potential in vitro. Int. J. Oral Maxillofac. Implants 25, 699-705.

Gotz, W., Kunert, D., Zhang, D., Kawarizadeh, A., Lossdorfer, S., and Jager, A. (2006a). Insulin-like growth factor system components in the periodontium during tooth root resorption and early repair processes in the rat. Eur. J. Oral Sci. 114, 318-327. doi:10.1111/j.1600-0722.2006.00381.x

Gotz, W., Heinen, M., Lossdorfer, S., and Jager, A. (2006b). Immunohistochemical localization of components of the insulin-like growth factor system in human permanent teeth. Arch. Oral Biol. 51, 387-395. doi:10.1016/j.archoralbio. 2005.10.005

Hamidouche, Z., Fromigue, O., Nuber, U., Vaudin, P., Pages, J. C., Ebert, R., et al. (2010). Autocrine fibroblast growth factor 18 mediates dexamethasone-induced osteogenic differentiation of murine mesenchymal stem cells. J. Cell. Physiol. 224, 509-515. doi:10.1002/jcp.22152

Jia, D., and Heersche, J. N. (2002). Expression of insulin-like growth factor system constituents in differentiating rat osteoblastic cell populations. Growth Horm. IGF Res. 12, 399-410. doi:10.1016/S1096-6374(02)00117-X

Joseph, B. K., Savage, N. W., Daley, T. J., and Young, W. G. (1996). In situ hybridization evidence for a paracrine/autocrine role for insulin-like growth factor-I in tooth development. Growth Factors 13, 11-17. doi:10.3109/08977199609034563

Khosla, S., Hassoun, A. A., Baker, B. K., Liu, F., Zein, N. N., Whyte, M. P., et al. (1998). Insulin-like growth factor system abnormalities in hepatitis C-associated osteosclerosis. Potential insights into increasing bone mass in adults. J. Clin. Invest. 101, 2165-2173. doi:10.1172/JCI1111

Lawrence, T. (2009). The nuclear factor NF-kappaB pathway in inflammation. Cold Spring Harb. Perspect. Biol. 1, a001651. doi:10.1101/cshperspect.a001651

Li, H., Bartold, P. M., Zhang, C. Z., Clarkson, R. W., Young, W. G., and Waters, M. J. (1998). Growth hormone and insulin-like growth factor I induce bone morphogenetic proteins 2 and 4: a mediator role in bone and tooth formation? Endocrinology 139, 3855-3862. doi:10.1210/endo.139.9.6211

Lovschall, H., Fejerskov, O., and Flyvbjerg, A. (2001). Pulp-capping with recombinant human insulin-like growth factor I (rhIGF-I) in rat molars. Adv. Dent. Res. 15, 108-112. doi:10.1177/08959374010150010301 
Ma, D., Gao, J., Yue, J., Yan, W., Fang, F., and Wu, B. (2012). Changes in proliferation and osteogenic differentiation of stem cells from deep caries in vitro. J. Endod. 38, 796-802. doi:10.1016/j.joen.2012.02.014

McLachlan, J. L., Sloan, A. J., Smith, A. J., Landini, G., and Cooper, P. R. (2004). S100 and cytokine expression in caries. Infect. Immun. 72, 4102-4108. doi:10.1128/ IAI.72.7.4102-4108.2004

Onishi, T., Kinoshita, S., Shintani, S., Sobue, S., and Ooshima, T. (1999). Stimulation of proliferation and differentiation of dog dental pulp cells in serum-free culture medium by insulin-like growth factor. Arch. Oral Biol. 44, 361-371. doi:10.1016/S0003-9969(99)00007-2

Reichenmiller, K. M., Mattern, C., Ranke, M. B., and Elmlinger, M. W. (2004). IGFs, IGFBPs, IGF-binding sites and biochemical markers of bone metabolism during differentiation in human pulp fibroblasts. Horm. Res. 62, 33-39. doi:10.1159/000078747

Selwitz, R. H., Ismail, A. I., and Pitts, N. B. (2007). Dental caries. Lancet 369, 51-59. doi:10.1016/S0140-6736(07)60031-2

Shi, S., Robey, P. G., and Gronthos, S. (2001). Comparison of human dental pulp and bone marrow stromal stem cells by cDNA microarray analysis. Bone 29, 532-539. doi:10.1016/S8756-3282(01)00612-3

Shoelson, S. E., Lee, J., and Goldfine, A. B. (2006). Inflammation and insulin resistance. J. Clin. Invest. 116, 1793-1801. doi:10.1172/JCI29069E1

Takahashi, K., Yamane, A., Bringas, P., Caton, J., Slavkin, H. C., and ZeichnerDavid, M. (1998). Induction of amelogenin and ameloblastin by insulin and insulin-like growth factors (IGF-I and IGF-II) during embryonic mouse tooth development in vitro. Connect. Tissue Res. 38, 269-78; discussion 295-303. doi:10.3109/03008209809017047
Tziafas, D., Alvanou, A., Papadimitriou, S., Gasic, J., and Komnenou, A. (1998) Effects of recombinant basic fibroblast growth factor, insulin-like growth factor-II and transforming growth factor-beta 1 on dog dental pulp cells in vivo. Arch. Oral Biol. 43, 431-444. doi:10.1016/S0003-9969(98)00026-0

Villafuerte, B. C., Koop, B. L., Pao, C. I., and Phillips, L. S. (1995). Glucocorticoid regulation of insulin-like growth factor-binding protein-3. Endocrinology 136, 1928-1933. doi:10.1210/endo.136.5.7536659

Wang, S., Mu, J., Fan, Z., Yu, Y., Yan, M., Lei, G., et al. (2012). Insulin-like growth factor 1 can promote the osteogenic differentiation and osteogenesis of stem cells from apical papilla. Stem Cell Res. 8, 346-356. doi:10.1016/j.scr.2011. 12.005

Werle, S. B., Lindemann, D., Steffens, D., Demarco, F. F., de Araujo, F. B., Pranke, P., et al. (2016). Carious deciduous teeth are a potential source for dental pulp stem cells. Clin. Oral Investig. 20, 75-81. doi:10.1007/s00784-015-1477-5

Conflict of Interest Statement: The authors declare that the research was conducted in the absence of any commercial or financial relationships that could be construed as a potential conflict of interest.

Copyright (C) 2018 Alkharobi, Al-Khafaji, Beattie, Devine and El-Gendy. This is an open-access article distributed under the terms of the Creative Commons Attribution License (CC BY). The use, distribution or reproduction in other forums is permitted, provided the original author(s) and the copyright owner are credited and that the original publication in this journal is cited, in accordance with accepted academic practice. No use, distribution or reproduction is permitted which does not comply with these terms. 